\title{
Biodegradation of explosive material 2,4,6-Trinitrotoluene (TNT)
}

\begin{abstract}
This mini-review aims to introduce biological treatments of the explosive substance 2,4,6-Trinitrotoluene (TNT), scientifically, it has been proven that this material is toxic, toxicity of its derivatives on evaluated living organisms, but it does not affect bacteria, fungi and yeast, therefore, these microorganisms can be used to treat toxic material TNT, and its derivatives which dissolve in water, it can be treated environmentally via one of the biotic methods, such as Bioreactor, Biological Composting, Biopilling and Phytoremediation for low concentrations in water and soil. Where micro-organisms convert TNT into other non-hazardous situation in the bioreactor, and the degradation of the (TNT) by turning carbon C14 located in the (TNT) and appearing in biomass of the cell as Acetic acid trichloroethylene where a material acquired by living cells in phytodegradation, in biopilling and composting, TNT is converted to Amino and diamino nitro toluene during the oxygen phase, Ventilation is eliminate changing materials Perhaps by the equivalent binding with the soil.
\end{abstract}

Keywords: TNT, biodegradation, bioreactor, land farming, biopilling, composting, phytoremediation
Volume 6 Issue 2 - 2018

\author{
Ahmed Ibrahim Jessim \\ Ministry of higher education and scientific research, science and \\ technology, Center of research and development, Iraq \\ Correspondence: Ahmed Ibrahim Jessim, Ministry of higher \\ education and scientific research, science and technology, \\ Treatment and disposal of chemical, biological and military \\ hazardous wastes, Center of research and development, \\ Baghdad, Iraq, Tel 9647 7I 36 597। 3, Email \\ ahm_jas7l@yahoo.com
}

Received: February 20, 2018| Published: March 26, 2018

\section{Introduction}

2,4,6-Trinitrotoluene (TNT) is a solid material, yellow, odourless and not found naturally, (TNT) was manufactured via aggregation of Nitric acid HNO3 and Sulfuric acid with Toluene $\mathrm{C}_{6} \mathrm{H}_{5}-\mathrm{CH}_{3} \cdot{ }^{1} \mathrm{TNT}$ was manufactured in 1916 at the beginning of First World War, TNT also was produced commercially and in governmental factories to use it in military ammunition in first and Second World War. ${ }^{2}$ TNT is a nitroaromatic compound, highly explosive six-membered ring, and its solid crystal material at room temperature and yellow colour. ${ }^{3}$ TNT considered as a nitroaromatic explosive which edited to the soil and water in the ecosystem, due to highly using basically in first and second war. Therefore, many used sites to produce TNT was polluted seriously and massively with TNT and related to it. Polluted sites with TNT may contain 10gm kgm-1 of TNT in soil and reach to $100 \mathrm{mg}$ liter-1 in water. TNT and its derivatives have a high toxicity and mutagens for prokaryotic and Eukaryotic at the same time. Therefore, there is an urgent need to clean polluted to ensure quality and environmental safety. There are estimates that nearly 3320 sites in Germany alone require restoration of a clean environment. A various chemical and physical processes have been developed to treat contaminated soil with TNT, but they are all very expensive, an activated charcoal for nitrogenous aromatic compounds has often been used to treat TNT in surface water and groundwater contaminated with these substances, unfortunately, the filling used in the purification Are very expensive and used carbon as highly problematic waste. ${ }^{4}$ A soluble phase of TNT is characterized by the presence of sludge containing TNT with environmental toxicity and contains directly about $67.8 \mathrm{mg}$ litre-1 from TNT. This sludge has specific toxicity for root elongation and germination. TNT is changed to4-amino-2,6-DNT and 2-amino-4,6-DNA with decreasing of total concentrations for nitrogenous aromatic compounds along 21 days, Bio-decomposition experiments are evaluation criteria for the further development of appropriate treatment technologies for these substances. Addition of isolated bacterial occultation from surrounding environment may accelerate processing of biodegradation because it is compatible with the material to be processed. The solid phase of TNT prevent microbial activity, therefore its transformation into the aqueous phase (water) accelerates its biological degradation processes. An enzymatic action of microorganisms is responsible for the degradation of TNT. ${ }^{5}$ Incomplete transitions of TNT derivatives in the environment are highly toxic to organisms such as fish and other animals, also it has an effect on fungus species Phanerochaete chrysosporium when the concentration is more than $20 \mathrm{ppm} .{ }^{6}$ Several studies have suggested that this substance may cause a very wide range of adverse health effects on certain environmental receptors such as Salmonella typhimurium strain TA1535/pTL210, algae, plants, invertebrate, some vertebrates and humans, but there are other studies were conducted on animals like Canis lupus, Mus musculus, Rattus and Rana temporaria, refers to TNT and its derivatives are mutilated to embryos, toxic to cells and may cause cellular mutation. ${ }^{7}$ Current studies have focused mainly on the bioremediation of this substance within the site. A wide range of fungi, plants, aerobic and anaerobic bacteria have been studied to determine effective technologies for biodegradation of TNT in the suite, generally, the fungi have high levels of aromatic nitrogenous explosives, but it cannot survive in harsh environmental conditions such as high temperatures and acidity. ${ }^{8}$ Aerobic bacteria also have the potential to convert TNT into an environmentally non-toxic substance. ${ }^{9}$ Also found that it is possible to immobilize road shape bacteria Bacillus sp. YRE1 on the surface of charcoal and polystyrene to use it directly in TNT biodegradation, and it found immobilization on charcoal and polystyrene raising from the efficiency of concentration reducing from $70.6 \%$ to $73.35 \%$ and degradation efficiency reaching to $94 \%$ in acidity at $\mathrm{pH}(5-7) \cdot{ }^{10}$ It was found that the bacteria isolated from the soils contaminated with TNT, gave amazing results by analyzing all the remaining TNT with $\mathrm{NO}_{3}$ release to the media. ${ }^{11}$ 
Many bacterial strains are characterized with high susceptibility to the treatment of this toxic substance environmentally, we find that the bacteria of the type Achromobacter spanius STE 11, the ability to reduce concentrations of explosive material 2,4,6-trinitrotoluene to $100 \mathrm{mg}$ litre -1 in along $20 \mathrm{~h}$. only in aerobic conditions, in this case, we found bacteria can occur 2,4,6-trinitrotoluene to 2,4-dinitrotoluene at the concentration $7 \mathrm{mg}$ litre -1 and $3 \mathrm{mg}$ liter-1 from 2,6-dinitrotoluene and 4-aminodinitrotoluene and $16 \mathrm{mg}$ litre- 1 of derivative material 2-aminodinitrotoluene. That's for bacteria $A$. spanius STE 11 ability to denitrate and occuration of TNT to DNT under aerobic conditions along growth period. This type of bacteria, these bacteria are characterized by their ability to collect nitrates $24.77 \mathrm{mg}$ liter- 1 of $\mathrm{NO}_{3}-1$ from nitrogen inside the cell, also can depend on TNT as a single resource of Nitrogen. It is possible to configure the conditions in which these bacteria degrade (TNT) in thermal range of $4-43^{\circ} \mathrm{C}$ and light acidic medium $\mathrm{pH}=(4-8)$, but the best reducing of TNT in acidic to neutral medium $(6-7)$ in $30^{\circ} \mathrm{C} .{ }^{12}$

\section{Used some of living microorganisms for TNT degradation}

Diverse living organisms which have the ability to decompose the chemical explosive (TNT), including bacteria such as Bacillus cereus, ${ }^{7,10}$ Clostridium sp., Desulfovibrio sp. and Methanococcus sp. ${ }^{4}$ Also, the genus Pseudomonas, ${ }^{7}$ and bacterial species Achromobacter spanius STE 11. ${ }^{7,12}$ Research's reported that Clavibacter agropyi which it's from Corynebacterium and Sphingomonas sanguinis. ${ }^{7,13}$ Also, other researchers reported Salmonella typhimurium can degregate TNT. ${ }^{7,14}$ Some fungal species such as Phanerochaete chrysosporium can degrade TNT partially not completely such as Bacteria also species from Stropharia. However, studies have shown that there are 91 fungal strains belonging to 32 species of environmental and taxonomic groups Such as those isolated from wood and decomposing garbage such as basidiomycetes and Saprophytic Micromycetes, these types of fungi have a good ability to convert TNT to another form (ADNT) Monoaminodinitrotoluenes, these fungi can produce more quantities of (ADNT) from basidiomycetes, results of these studies viewed that Two fungal strains Clitocybula dusenii TMb12 and Stropharia rugosa-annulata DSM11372,7,15 also fungus type Phanerochaete chrysosporium which classified as from white-rot species, ${ }^{6}$ and a group belong to basidiomycetes such as Agaricus aestivalis, Agrocybe praecox, Clitocybe odora, Stropharia, Shewanella putrefaciens CN 32, Aspergillus, Alternaria, Penicillium, Trichoderma, and from tolerant acidity yeasts Yarrowia lipolytica AN-L15 have the ability to degrade TNT. ${ }^{7}$

\section{Types of biodegradation for explosive material (TNT)}

\section{1st - biodegradation via bioreactor}

\section{A. Biodegradation of TNT under anaerobic conditions}

Biodegradation of TNT under non aerobic conditions can cause to degrade Nitro aromatic compounds in soil completely, this is done ex-site to degrade 2,4,6-trinitrotoluene (TNT) in polluted soil. Where the bioreactor is loaded with approximately $23 \mathrm{~m}^{3}$ of polluted soil with TNT by equal ratio $50: 50$ of mud and water, then enhanced it by $1-2 \%$ (wet/volume) of Carbon starch, buffered with phosphate to fine acidity close to neutral. A native soil with all microorganisms is used, then conditions are controlled as non aerobic for 1-2 days. Microorganisms can degrade $3000 \mathrm{mg} \mathrm{kg}-1$ of TNT along 11 weeks. The reason of slow processing somewhat belong to low ambient temperatures, alsohigher level of clay in soils contaminated with a high percentage of other pollutants in the soil with high concentrations from TNT in the soil. ${ }^{16}$ There are two types of Bioreactors, first one is a reactor of soil column (Figure 1), and the second type is slurry bioreactor (Figure 2) which depend on biotic reactions of living microorganisms but it needs much more water with continuing the addition of oxygen along the period of degradation. ${ }^{17}$

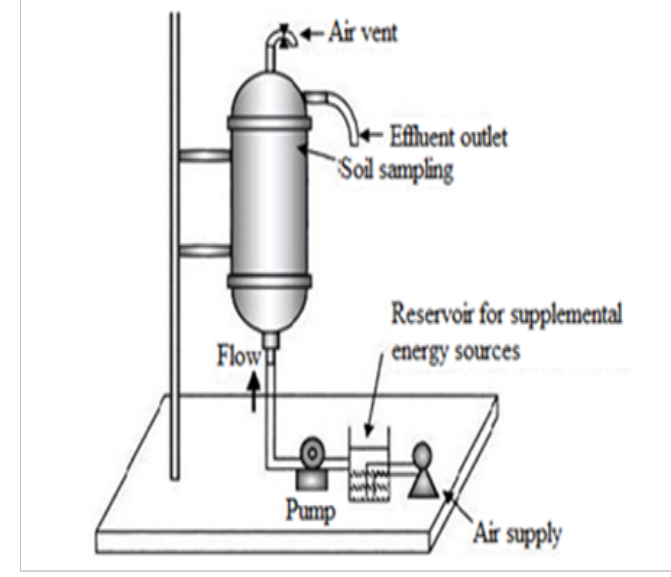

Figure I Schematic diagram of soil column reactor. ${ }^{17}$

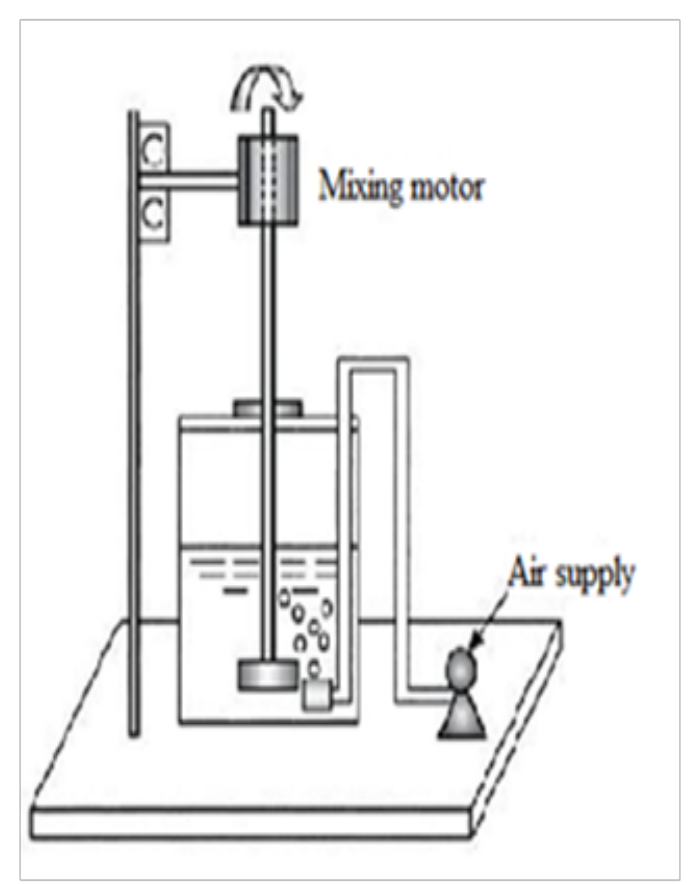

Figure 2 Schematic diagram of soil slurry reactor. ${ }^{17}$

\section{B. Biodegradation of TNT under aerobic condition}

Degradation via living microorganisms under aerobic conditions can be controlled more by the staff with the provision of additional sources for nutrition of living microorganisms in a slurry bioreactor, for example, where the bacteria Stenotrophomonas $s p$. canconvert 2,4,6-trinitrotoluene TNT to 2-amino-4,6-dinitrotoluene to 4-amino2,6-dinitrotoluene (Figure 3). ${ }^{18}$ 


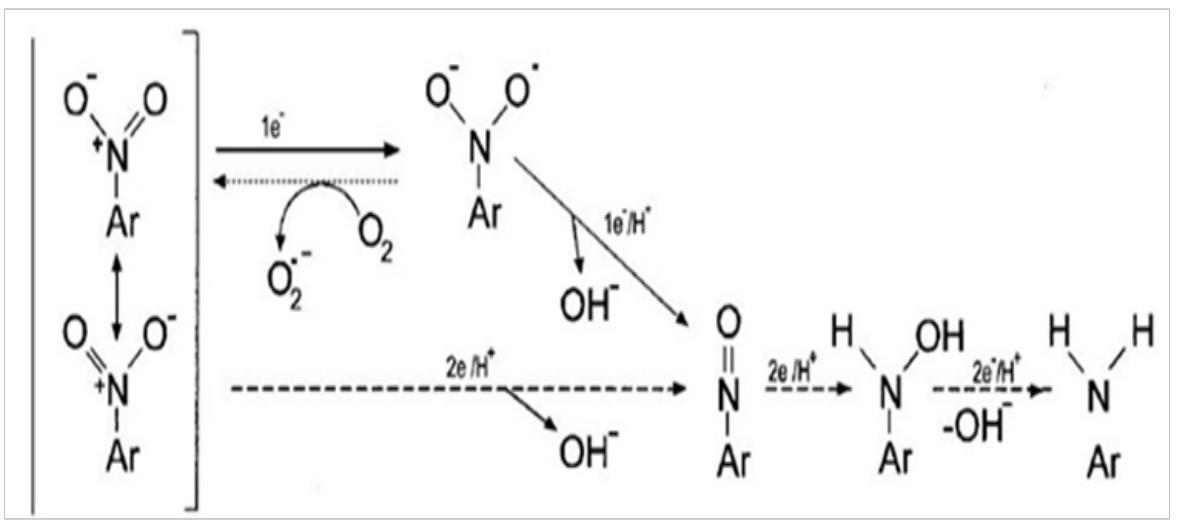

Figure 3 Mechanisms for the reduction of nitro groups in nitroaromatic compounds. The first step in nitro group reduction can be achieved through oneelectron transfer (solid line) or two-electron transfer (dashed line). The first mechanism produces a nitro anion radical that could react with oxygen to form a superoxide radical and the original nitroaromatic compound through a futile cycle (dotted line). If the mechanism occurs via the transfer of two electrons, the nitroso derivative formed is the first putative intermediate; following two consecutive electron transfers, a hydroxylamine and an aromatic amine are produced. ${ }^{29}$

\section{2nd Land farming}

Land farming is considered as a solid phase of degradation process which polluted soil mix with nutrients and with appropriate moisture content with tillage and flipping, also enhanced with molasses, smashed herbs grasses in order to improve soil properties to use in degradation. The decomposition of TNT via pathway of transform C14 presence in TNT and presence of C14 in biomass of cells as Trichloroacetic acid $\mathrm{Cl} 3$ ccooh as a material that can be gained by living cells, Due to the solubility of TNT and its derivatives in water, water must be controlled hydraulically on the feeding or in site. ${ }^{19}$ This technology is characterized by simplicity as it depends on spreading polluted soils with TNT or spray the TNT after being dissolved in water at range from $3.1-33.3^{\circ} \mathrm{C}$,over the $\mathrm{pH}$ range of $(4.2-6.2),{ }^{20}$ and then the earth is plowed and sprayed with water periodically to maintain moisture in order to maintain the effectiveness of living organisms in decomposition of TNT. ${ }^{21}$

\section{3rd Biological composting}

Biological composting is consider as very useful technology to degrade polluted soils with non-depleted TNT. Projects have been done in this field, refers to the ability to remove TNT from soils. In biological composting, the polluted soil must mix with the same volume of additional material, which must Contaminate soil should be mixed with a similar volume of additional materials, which are usually by-products of agricultural processes (hay, clover, wood chips, sugar beet stalks, leaves). Pneumatic air-fertilization systems and aerobic anaerobic fertilization systems are highly efficient in treating soil contaminated with TNT. Under these conditions, the substance is converted to Amine and di-Ammonium nitrate Toluene during the oxygenation phase, and the ventilation eliminates the transformation products, possibly by the equivalent correlation with the soil. ${ }^{22}$ The composting need temperature $>30^{\circ} \mathrm{C}$, plentiful nutrients, high level of moisture approximately $>50 \%$, sufficient oxygen in neutral $\mathrm{pH} .^{21}$

There are several factors which need to mix ingredients to provide microorganisms with optimum environmental conditions to live. The most important factor is Carbon $\mathrm{C}$ to Nitrogen $\mathrm{N}$ ratio, but the other factors are influencing the choice of soil amendments to include moisture, $\mathrm{pH}$, degradability, the percentage of organic matter, and availability of specific soil amendments. The composting feed stocks used were 30 percent of contaminated soil, 21 percent from cattle manure with 18 percent of sawdust with 18 percent of alfalfa, and 10percent from potato waste also 3 percent of chicken manure. It may need a large temporary mobile building to construct to control fumes and ensure optimum conditions for the composting process. The mixture of contaminated soil and soil amendments need to places into windrows. Workers should use highly specialized mixing equipment, turned these steaming piles three times daily to: (1) ensure that the compost received sufficient oxygen; (2) release trapped heat, water vapour, and gases; and (3) to break up clumps. ${ }^{23}$

\section{4th Biopilling}

Biopilling considered as more active for biodegradation of explosive materials like TNT, and each pollutant required slight modification on basic technique. Biopilling technique is efficient economically because of low cost for combination biopilling parts. Also the Low operating cost of the technologies that used in the processing of degradation. There are more degradation plants being built in the world that reduce transport costs, and that explosive material (TNT) must be very homogeneous with soil for biodegradation processing. . $^{24,25}$

\section{Requirements of biodegradation for polluted soils with TNT by biopilling}

According to, ${ }^{26}$ and for complete this procedure, we must prepare a flexible plastic PVC tubes of different diameters type with air compressors with a capacity calculated according to the number of available pollutants, joined together with valves to close and open air in order for ventilation. Also requires existence pipelines to push nutrients and water into the piles, also required basins to collect perfusion of dissolved TNT to re-pump it to the piles as a modified procedure. ${ }^{26}$

\section{Pecification of Biopilling method}

Biopilling is a technique can be used to degrade massive quantity of polluted soils with TNT, and it is characterized by the fact that it does not need to flip the soil as it is in land farming and biological composting. We must mention here that, biodegradation shall be at the top, center and bottom of the pilling. Piles are usually prepared as a form of pyramids or trapezoids, the heights vary between 0.8 and $2 \mathrm{~m}$ depending on the type of aeration used, is it passive or active. The dynamic biopiles are consistently plowed and turned to maximize their exposure to increase the bioavailability of the contaminants by constantly exposing them to oxygen, water, nutrients, and microbes. ${ }^{26}$ 
The important thing it is no matter which types of heaps we can used, but the heap should preparer on area must covered with asphalt or concrete to prevent the seepage of contaminants, also the area above the heaps must be covered in order to control temperature and moisture content conditions. ${ }^{25}$

\section{Defects of biopilling method}

From, ${ }^{25,26}$ biopilling cannot do without of tools or essential nutrients in a Biopilling method where one of them is complementary to the others, in the case of missing one of these tools or essential nutrients, biodegradation will not go on well. Cleaning and maintenance of pipes that may become obsolete and it may need additional pipes at a time to enhance the shortage after the dismantling of damaged pipes at the end of the process, that mean steps must be taken to prepare piles, add nutrients and herbs sequentially to ensure microbes grow well and degrade TNT.

\section{Steps of procedure of biopilling}

In Biopilling, Prepare a suitable piece of land for the event, it is relatively flat and has the ability to retain rainwater, and construction soil barrier with suitable height to reserve surface water and water leachate. Here process needs to cover the piles with a multi-layered polyethylene cover with a minimum thickness of $8 \mathrm{~mm}$ on the sand layer with a height of 2-3ng. It is durable and shall bear the weight of the soil brush equipment and not permeable to the soil filter. When polluted soils with TNT prepared from bottom to top, the stuff shall prepare air distribution tubes, calcium carbonate, compost and water for each level. When the pipes are connected, they are cracked and wrapped with a flexible cloth inside the piles, with some air batches with one direction valves, particle filters and a moisture trap. A mechanical mechanism must be connected to the pressure balance for not bursting or breaking the pipe into the piles. Soil layers should be wetted with raw water droplets (preferably river water not contaminated with other materials) so that they are not muddy and wet only to complete the process. Allow the movement of air between the pile of soil and the cover by placing tires or hay bales between the pile and the cover. Test the decomposition ratios for both contaminated and leached water in a manner that allows taking samples and not lowering the temperature inside the pile, as a modified procedure. ${ }^{26}$

\section{Phytoremediation of TNT}

Phytoremediation is a technique use in-suite which use plants to degrade polluted soils with TNT. This method considered as most appropriate methods for sites where other methods of degradation options are not available and effective in terms of low-cost or contaminated sites or in combination with other treatment technologies. Deep-rooted trees, grasses, legumes and aquatic plants all have applications in the field of phyto remediation. Phytoremediation technique was used to degrade a wide range of organic polluted and explosive materials like TNT, were planets can remove pollutants from groundwater and underground reservoirs, also roots can give support to a wide range of microorganisms in the earth literature. ${ }^{27}$

\section{Mechanisms of TNT degradations}

According to, ${ }^{24}$ "the $\pi$ electrons from the aromatic ring of TNT can remove by electronegative nitro groups, a process that makes the nucleus electrophilic. The nitro group consists of two different elements, $\mathrm{N}$ and $\mathrm{O}$, which are both highly electronegative. Oxygen is even more electronegative than the nitrogen atom; hence, the N-O bond is polarized. The partially positive charge of the nitrogen atom, combined with its high electronegativity, makes the nitro group easily reducible". Nitro group's reduction on aromatic rings is distributed widely among living organisms ${ }^{28,29}$ This reduction is referred to as first type, this type independent on oxygen, and does not form radicals. The nitrite reductase enzymes are capable of performing this electronic duplex donated by reduced pyridine nucleotides, also includes other reduction enzymes that reduce nitroaromatic compounds include aldehyde oxidase, dihydro-lipic amide dehydrogenase, cytochrome b5 reductase, diaphorases, hydrogenases, xanthine oxidase, and $\mathrm{CO}$ dehydrogenase. Nitro group can also be reduced in vitro through single-electron transfers, which form a nitro anion radical. This radical is a putative intermediate in the reduction of a nitro group to a nitroso group, but it canreact with oxygen to produce a superoxide anion and alter the original nitroaromatic compound. The enzymes that catalyze this reaction are known as oxygen sensitive (type II) nitro reductases and are found in bacteria such as Clostridium and Escherichia coli. Abiotic redaction can occur for nitro groups to the corresponding amines in sediments, soils, and aquifers. There are many potential donors of electrons in natural systems for (eg. Iron and sulfur reduced species, and natural organic materials), which may reduce from nitroaromatic compounds via biodegradation. TNT material reacts with the siloxane surface of clays to produce covalent groups. Living Microorganisms play a very important role in these biochemical processes but they are still unexplored relatively. ${ }^{20}$

\section{Conclusion}

Biodegradation have an effective role in disposing of organic pollutants by concentrations and type, from these organic pollutants nitro aromatic materials such as TNT, these biodegradations considered very efficiently and the final outputs are environmentally harmless until gradually fade. Fungi, bacteria and some yeasts play a major role in the completion of biodegradation with appropriate, moisture content, with no leakage of water containing dissolved TNT and its derivatives to the surrounding environment, with the limitation of biodegradation in pollution area and far away from water resources. The first aim of degradation is to change explosion property in normal case of TNT for large quantity after dissolving it in water before mix it with soil, for pure TNT, but for polluted soil with TNT is easier in preparation steps.

\section{Recommendations}

These biodegradations are preferred to use because they are without hydrocarbon emission products and do not cause any potential damage and side effects, but its take a long period somehow about (13 ) months. However, this bio degradations characterized by the lack of carbon emission to the atmosphere with no remaining of pollutant in the environment with high concentration.

\section{Acknowledgements}

None.

\section{Conflict of interest}

There is no conflict of interest to publish the article in this Journal.

\section{References}

1. ATSDR. High-performance liquid chromatography (HPLC) and highresolution gas chromatography (HRGC) have been paired with several types of detectors, including mass spectrometry (MS), electrochemical 
detection (ED), electron capture detectors (ECD) and ultraviolet (UV) detectors; 1995.

2. Steen K. Technical expertise and US mobilization, 1917-18: High explosives and war gases. Frontline and Factory: Comparative Perspectives on the Chemical Industry at War, 1914-1924. 2006;16:103122.

3. CRREL. Conceptual model for the transport of energetic residues from surface soil to groundwater by range activities. ERDC/CRREL TR-06-18; 2006.

4. Clause H. Microbial degradation of 2,4,6- Trinitrotoluene in vitro and in natural environments. In: Singh SN, editor. Biological remediation of explosive residues, environmental science and engineering. Springer International Publishing. 2014:15-38.

5. Nehrenheim, E, Muter, O, Odlare,et al. Toxicity assessment and biodegradation potential of water-soluble sludge containing 2,4,6-trinitrotoluene. Water science and technology. 2013;68(8):17071714

6. Williamson KJ. In vitro anaerobic trinitrotoluene (TNT) degradation with rumen fluid and an isolate, G.8. An abstract of the thesis of taejin lee for the degree of doctor of philosophy in civil engineering. Oregon State University, USA; 1995:14-15.

7. Habineza A, Zhai J, Mai T, et al. Biodegradation of 2, 4, 6Trinitrotoluene (TNT) in contaminated soil and microbial remediation options for treatment. periodica polytechnic chemical engineering. 2016;61(3):171-187.

8. Gumuscu B, Tekinay T. Effective biodegradation of 2,4,6-trinitrotoluene using a novel bacterial strain isolated from TNT-contaminated soil. International Biodeterioration \& Biodegradation 2013;85:35-41.

9. Smets BF, Yin H, Esteve-Nunez A. TNT biotransformation: when chemistry confronts mineralization. Applied Microbiology and Biotechnology. 2007;76(2):267-277.

10. Ullah H, Shah AA, Hasan F, et al. Biodegradation of trinitrotoluene by immobilized Bacillus sp. YRE1. Pak J Bot. 2010;42(5):3357-3367.

11. Rahal AGh, Moussa LM. Degradation of 2,4,6-Trinitrotoluene (TNT) by soil bacteria isolated from TNT contaminated soil. Australian Journal of Basic and Applied Sciences. 2011;5(2):8-17.

12. Gumuscu B, Tekinay T. Effective biodegradation of 2,4,6-trinitrotoluene using a novel bacterial strain isolated from TNT-contaminated soil. International Biodeterioration \& Biodegradation. 2013;85:35-41.

13. Moussa LA. Degradation of 2,4,6-Trinitrotoluene (TNT) by soil bacteria isolated from TNT contaminated soil. Australian Journal of Basic and Applied Sciences. 2011;5(2):8-17.

14. Litake GM, Joshi SG, Ghole VS. TNT biotransformation potential of the clinical isolate of Salmonella typhimurium - potential ecological implications. Indian Journal of Occupational and Environmental Medicine. 2005;9(1):29-34.

15. Van Aken B, Agathos SN. Biodegradation of nitro-substituted explosives by white-rot fungi: a mechanistic approach. In: Laskin AI, Bennett JW, Gadd G, editors. Advances in applied microbiology. San Diego Academic Press. 2001;49:1-77.

16. Funk SB, Crawford DL, Crawford RL, et al. Full-scale anaerobic bioremediation of trinitrotoluene (TNT) contaminated soil. Applied Biochemistry and Biotechnology. 1995;51(1):625-633.

17. Park C, Kim TH, Kim A, et al. Bioremediation of 2,4,6-Trinitrotoluene contaminated soil in slurry and column reactors. Journal of Bioscience and Bioengineering. 2003;96(5):429-433.

18. Lee MS, Chang HW, Kahng HY, et al. Biological removal of explosive 2,4,6-trinitrotoluene by Stenotrophomonas $s p$. OK-5 in bench-scale bioreactors. Biotechnology and Bioprocess Engineering. 2002;7(2):105111.

19. Esteve-Núñez A, Caballero A, Ramos JL. Biological degradation of 2,4,6-Trinitrotoluene. Microbiology and Molecular Biology Reviews. 2001;65(3):335-352.

20. Lynch JC, Myers KF, Brannon JM, et al. Effects of $\mathrm{pH}$ and temperature on the aqueous solubility and dissolution rate of 2,4,6-Trinitrotoluene (TNT), Hexahydro-1,3,5-trinitro-1,3,5-triazine (RDX), and Octahydro1,3,5,7-tetranitro-1,3,5,7-tetrazocine (HMX). J Chem Eng Data 2001;46(6):1549-1555.

21. Craig HD, Sisk WE, Nelson MD, et al. Bioremediation of explosives contaminated soils. Proceedings of the 10th Annual Conference on Hazardous Waste Research. Kansas State University, Manhattan, Kansas; 1995:164-179.

22. Semple KT, Reid BJ, Fermor TR. Review impact of composting strategies on the treatment of soils contaminated with organic pollutants. Environmental Pollution. 2001;112:269-283.

23. Williams RT, Ziegenfuss PS, Sisk WE. Composting of explosives and propellant contaminated soils under thermophilic and mesophilic conditions. Journal of Industrial Microbiology. 1992;9(2):137-144.

24. Van Deuren J, Lloyd T, Chhetry S, et al. Remediation technologies screening matrix and reference guide, Federal Remediation Technologies Roundtable. 2002; 4

25. Schulz-Berendt V. Bioremediation with heap technique. Biotechnology. 2000;11b:320-328.

26. Koning M, Hupe K, Stegmann R. Thermal processes, scrubbing/ extraction, bioremediation and disposal. Biotechnology. 2000;11b:306317.

27. Schnoor JL. Degradation by plants-phytoremediation. Biotechnology. 2000;11b:372-384.

28. Roldán MD, Pérez-Reinado E, Castillo F, et al. Reduction of poly nitroaromatic compounds: the bacterial nitroreductases. FEMS Microbiol Rev. 2008;32:474-500.

29. Spain JC. Biodegradation of nitroaromatic compounds. Annu Rev Microbiol 1995;49:523-555. 